\title{
Latin Harfli Kırgızca Nutuk-Kyep Adlı Eser Üzerine
}

\section{ALİ ÇELİK*}

Öz

Bu çalışma, Baktıgül Kalambekova tarafından 2001 yılında Kırgızca olarak yayımlanan Nutuk-Kyep adlı eser üzerinedir. Dikkat çeken husus ise çalışmanın Latin harfli olarak hazırlanmasıdır. Temelde eserin Kırgızcaya aktarımında iki biçimi bulunmaktadır. Bunlar hem Latin hem de Kiril harflidir. Yani eser tek dilde olup iki farklı ciltte farklı alfabelerde yayımlanmıştır. Özellikle Latin harfli Kırgızca basımında birtakım sorunlar tespit edilmiştir. $\mathrm{Bu}$ sorunlar, Nutuk'ta geçen ilgili cümleler üzerinden açıklanmaya çalışılacaktır. Temel alınan Latin harfli Kırgızca metin ile Kiril harfli Kırgızca metin karşılaştırılacak ve kimi kelimelerdeki farklılıklar ile alfabedeki aktarım farklılıkları üzerinde durulacaktır.

Anahtar Sözcükler: Nutuk, Atatürk, Latin, Kiril, Kırgızca

\section{ON THE KYRGYZ TEXT ENTITLED AS “NUTUK-KYEP” WITH LATIN ALPHABET}

\section{Abstract}

This work is about Nutuk-Kyep published in 2001 in Kyrgyz language by Baktıül Kalambekova. The noteworthy feature of the work is that it is prepared with the Latin alphabet. Basically, there are two forms of the work in transcription to Kyrgyz language. These are both Latin and Cyrillic. In other words, the work has a single language but published in different alphabets in two different volumes. Some problems were especially determined in the publication of Kyrgyz language with Latin alphabet. These problems will be tried to be explained through the related sentences in Nutuk. The texts of Kyrgyz language with Latin and Cyrillic alphabets will be compared and differences in some words and transcription differences in the alphabet will be scrutinized.

Keywords: Nutuk, Atatürk, Latin, Cyrillic, Kyrgyz Language

\section{GİRIŞ}

ワürkçe Sözlük'te nutuk, “1. Söz, konuşma 2. Söylev” (TS, 2011: 1782) şeklinde; söylev ise "bir topluluğa düşünceler, duygular aşılamak amacıyla söylenen, L uzunca, coşkulu ve güzel söz, nutuk, hitabe" (TS, 2011: 2153) olarak tanımlanmaktadır.

\footnotetext{
* Türkiye-Kırgızistan Manas Üniversitesi, alicelik1989@mynet.com, orcid.org/ 0000-0002-4963-1423 
Baktıgül Kalambekova tarafından 2001 yılında Kırgızcaya aktarılan "Nutuk-Kyep" adlı eser, ayrı basımlar olarak Latin ve Kiril harfli olarak basılmıştır. Latin harfli baskısında tespit edilen bazı sorunlar ilgili cümleler üzerinden açıklanmaya çalışılmıştır.

İki eserde harflerin yazımında karşılaştırmalar yapılırken Kiril harfli metin için "KHM", Latin harfli metin için ise "LHM" kısaltmaları kullanılacaktır.

Hatalar ele alınırken LHM'nin tamamı incelenmiş; ancak bu çalışmada çok fazla sayfa tutacağ1 için metinden 13 adet cümle seçilmiştir. İlgili eserde önce KHM ardından LHM verilecektir. Ardından hangi farklılıklar varsa onlar belirtilecektir. Eserde tespit edilen bazı hatalar şunlardır:

1. Eserin "Baş söz" kısmına bakıldığında sayfalar numaralandırılmamıştır. Ayrıca başlıktaki hata şöyledir:

КНМ. Баш сөз (1. satır, ilk sayfa)

LHM. Baş cöz (1. satır, ilk sayfa)

Başlık yazılırken LHM'de söz kelimesi için "s" harfi yazılması gerekirken " $c$ " yazılmıştır. Metin içerisinde istemeden de olsa kimi zaman birtakım yazım hatalarının olması mümkündür. Ancak başlıkların hatadan arındırılmış olması gerekir. Çünkü başlıklar, metinlerin ilk parçalarıdır.

2. КНМ. Колуңардагы китеп- бүтүн адамзат ичинен жыйырминчы кылымда чыккан эң көрүнүктүу саясатчьларынын бири, түрк улутунун азамат перзенти, мөлдө түрк дүйнөсүнүн мактанычы, жаң,ы Түркия маллекетинин куруучусу жана туңгуч Президенти Мустафа Кемал Ататүрктүн улуу мурасы- Нутук (Речь же Ken) (Baş söz, 1-6. satırlar, ilk sayfa).

LHM. Koluñardag1 kityep- bütün adamzat içinyen jıyırmançı kılımda çıkkan eñ körünüktüü sayasatçılardın biri, türk ulutunun azamat pyerzyenti, möldö türk düynösünün maktanıçı, jañ Türkıya mamlyekyetinin kuruuçusu jana tunguç Prezidenti Mustafa Kemal Atatürktün uluu murasi- Nutuk (Rech jye Kyep) (Baş söz, 2-6. satırlar, ilk sayfa).

Yukarıda verilen iki cümleye bakıldığında

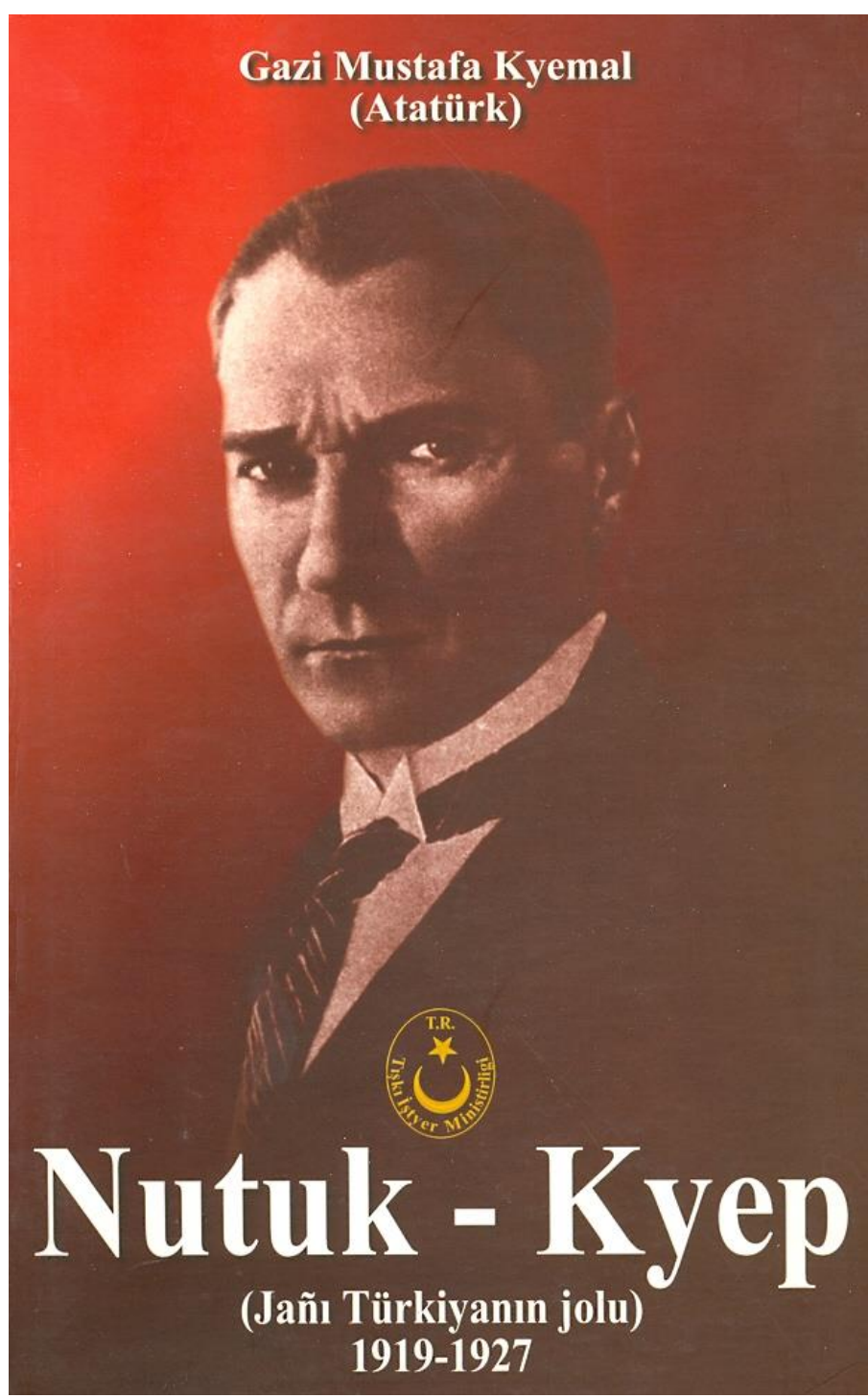

Baktıgül Kalambekova tarafından yayımlanan Nutuk-Kyep 
LHM'de özellikle "e"lerin yazımıyla ilgili bir sorun göze çarpmaktadır. Bugünkü Kırgızcada "E-e" harfi latin harfine aktarılırken kelime başında ya da ünlü harften sonra "Ye-ye"li; ünsüzden sonra ise "E-e"li biçimde yazılır. Ancak örnek cümlelere bakıldığında LHM'deki китеп-kityер, ичинен-іс̧іпуеn, перзенти-pyеrzyenti, мамлекетинин- mamlyekyetinin, же-jye, Ken-Kyep kelimeleri harf çeviriminde paralellik sağlamamaktadır. İşin ilginç tarafı kelime ortası "e" harfleri için "ye" biçimi kullanırken Президенти-Prezidenti, Keмas-Kemal, РечьRech kelimelerinde ise "ye"li değil "e"li biçim görülmektedir. Yani bu üç kelime doğru yazılmıştır.

Kırgızcadaki "Ж-Ж" harfi, latin harfine "C-c" olarak aktarılması gerekir. Жыйырманчь- jıyırmançı, жаңъь-јап̃ı, жана-jana kelimeleri hatalı biçimde “ $\mathrm{j}$ ” ile yazılmıştır. Kırgızca kökenli bu kelimelerin "j” ile gösterilmesi kesinlikle yanlıştır. Kırgızcada bu kelimeler "j"li değil "c"li olarak telaffuz edilip yazılmaktadır.

ТҮркия-Türkıya kelimelerine bakıldığında Latin harfine aktarımda Türkiya biçimde olmalıdır. Kırgızcadaki “И-и” harfleri Latin harfinde her zaman "İ-i” biçimde olur.

Саясатчыларының-sayasatçılardın bu iki kelime incelendiğinde ek probleminin olduğu görülmektedir. +bıның (+ının) mı yoksa $+d \imath n$ eki mi kullanılmalıdır? Aynı tarihte ve dilde basılan eserin sadece farklı iki alfabede yazılıp böyle bir farkın olması ilginçtir.

3. КНМ. Анткени бул китеп аркылуу улутташтарыбыз кеменгер Ататүрктүн өз өлкөсүнүн кескин жаңылануу, кайрадан жаралуу, ццивилизациялашкан дүйнөгө кошулуу маселелерине тиешелүү айткан залкар ой-пикирлерин эне тилинде окуп үйрөнүҮ мүмкүнчүлүгүн алып отурат (Baş söz, 11-15. satırlar, ilk sayfa).

LHM. Antkyeni bul kityep arkıluu uluttaştarıbız kyemyengyer Atatürktün öz ölkösünün kyeskin jañılanuu, kayradan jaraluu, sivilizacıalaşkan düynögö koşuluu masyelyelyerine tiyeşelüü aytkan zalkar oy-pikirlyerin enye tilindye okup üyrönüü mümkünçülügün alıp oturat (Baş söz, 10-14. satırlar, ilk sayfa).

LHM'de "e"nin "ye"li biçime hatalı olarak aktarıldığı görülmektedir: АнткениAntkyeni, китеп-kityер, кеменгер-kyетуепяуеr, кескин-kyeskin, маселелерине-таsyelyelyerine, тиешелүY-tiyeşelü̈, пикирлерин-pikirlyerin, эне-епуе, тилинде-tilindye. Verilen bu kelimelerde Latin harfine aktarımında paralellik sağlanamamaktadır; ancak masyelyelyerine ve tiyeşelü̈̈ kelimelerine bakıldığında maselelerin+e yapısıdaki yönelme hali eki ile tiyeşelü̈̈ kelimesi doğru aktarılmıştır. Yönelme hali eki ile tiyeşelüü kelimesi doğru yazılırken, farklı kelimelerdeki “e"nin neden "ye"li biçimde aktarıldığı düşündürücüdür. Ayrıca цุивилизациялашкан-sivilizacıalaşkan kelimesinin ilk harfi olan "ц", "ts" biçiminde aktarılmalıdır. Örnekte ise "s"li olarak verilmiştir. "ц" harfi hiçbir zaman "s"ye denk olamaz. Aynı örneğin orta kısmına bakıldığında da "ц" harfi bu sefer de "c"ye karşılık 
verilmiştir. Bu da yanlıştır. "Цивилизациялащкан" kelimesi "tsivilizatsiyalaşkan" biçiminde aktarılmalıydi.

4. КНМ. Ошол кездеги империалисттик күчтөр оккупациялаган Осмон империясының ордуна улуттук Түркия Жумуриятын түптөө, тикелөө, өөрчүтүҮ иши канчалык мүшкүл, канчалык татаал, драмалуу болгондугу айдан ачык баяндалат (Ваş söz, 38-41. satırlar, ilk sayfa).

LHM. Oşol kyezdyegi impyerıalistik küçtör okkupacialagan Osmon impyeriasının orduna uluttuk Türkiya Jumutiyatın tüptöö, tikyelöö, öörçütüü işi kançalık müşkül, kançalık tataal, dramaluu bolgondugu aydan-açık bayandalat (Baş söz, 35-38. satırlar, ilk sayfa).

LHM'de "e"nin "ye"li biçime hatalı olarak aktarılan örnekler: кездеzu-kyezdyegi, империалисттик-ітруеrıalistik, оккупациялаган-оkkupacialagan, империясынын-ітруеriasının, тикелөө-tikyelö. Bu durumun yanında Rusça vasıtasıyla Kırgızcaya giren bazı kelimelerin Latih harfine aktarımında da hatalar görülmektedir: uмnериалисттик-impyerıalistik, оккупациялаган-оkkupacialagan, империясынын-impyeriasının. Daha önce de belirtildiği gibi "ye"li yazım bulunmakla birlikte "i"li yazımın Latin alfabesine aktarımında " 1 "lı şekli görülmektedir. İkinci örnekte "ц" harfine karşıllk " $\mathrm{c}$ " harfine aktarım görülmektedir. Bu da hatalı bir durumdur. Çünkü “ц" harfi "ts" ye karşıllı gelmektedir. Kırgızcaya "ts"li biçimler Rusçadan gelmiştir. Sonuncu örneğe bakıldığında " $я$ " harfine sahip kelime, Latin alfabesine aktarılırken "a"lı olarak verilmiştir. Aslında "ya"lı biçim olması gerekirken eksik harflendirme sonucu " $a$ "lı biçim görülmektedir.

Жумуриятын-Jumutiyatın örneğinde ise kelime başında " $\mathrm{c}$ " harfinin olması gerekir. Ayrıca ilgili kelime Latin harfli olarak "Jumuriyat" şeklinde yazılmalıydı.

5. КНМ. Демек, бул китепти окуп, маани-маңызын жакшылап түшүнүү кыргыз окурмандар үчүн кызыктуу да, пайдалуу да болооруна терен ищенем (Baş söz, 35-37. satırlar, ikinci sayfa).

LHM. Dyemek, bul kitepti okup, maani-mañızın jakşılap tüşünüü kırgız okurmandar üçün kızıktuu da, paydaluu da bolooruna tereñ işyenyem (Baş söz, 32-34. satırlar, ikinci sayfa).

Bu örnekte "e"li biçimin hem doğru hem de hatalı biçimleri bir arada görülmektedir. Hatalı olarak Демек-Dyemek, ишенем-işyenyem kelimelerindeki "e"li biçimler "ye"li olarak verilmiştir. Diğer taraftan китепти-kitepti, терен̧-tеreñ kelimelerinin Latin harflerine aktarımı tamamen doğrudur. Aynı cümlede aynı harfe karşılık iki farklı biçimde aktarma yapilmıştır.

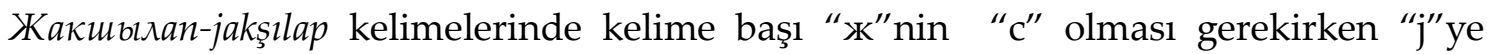
aktarımı yapılmış ve aynı hata diğer örneklerde olduğu gibi tekrarlanmıştır. 


\section{6. КНМ. Аскар Акаев}

Кыргыз Республикасының Президенти (Baş söz, 38-39. satıralar, ikinci sayfa).

LHM. Askar Akayev

Kırgız Respublikasının Prezidenti (Baş söz, 35-36. satırlar, ikinci sayfa).

Şimdi, bu örneğe bakıldığında Kirilden Latin alfabesine aktarımında herhangi bir sorun görülmemektedir. Özellikle önceki örneklerde Kiril harfli "e"nin Latin alfabesine aktarımında bazı problemler görülmüştü. Ancak burada aynı problem bulunmamaktadır. Peki durum neden böyledir? Önceki cümlelerde verilen hatalı örneklerden bir farkı var midir?

7. Eserin "Kiriş söz" kısmında sayfalar numaralandırılmamıştır. Burada başlık olarak verilen kelimeyle ilgili şunlar belirtilebilir:

КНМ. Кириш сөз (Kiriş söz, 1. satır, ilk sayfa).

LHM. Kiriş söz (Kiriş söz, 1. satır, ilk sayfa).

$\mathrm{Bu}$ örnekte herhangi bir hata yoktur. Yukarıda 1 numaralı örnekte verilen "Баш сөз-Ваş cöz" kelimelerine değinildiğinde "c"nin "s"ye aktarımı olması gerekirken "c" biçiminde verilmiştir. Bu durum belki dikkatsizlik sonucu ortaya çıkmış olabilir. Yine de bir metnin başlığının hatalı oluşu, göze çarpan önemli noktalardandır.

8. КНМ. Окурман алгачкы жолу кыргызча котормосу менен таанышып турган ушул чыгарма- улуу инсан Мустафа Кемал Ататүрктүн өз колу менен жазылып, анан 1927-жылдын 15-октябрынан 20-октябрына чейинки беш күн ичинде Жумурият Калк Партиясынын экинчи курултайында окулган көлөмдүҮ кайрылуусу (Kiriş söz, 2-6. satır, ilk sayfa).

LHM. Okurman algaçkı jolu kırgızca kotormosu myenyen taanışıp turgan uşul çıgarmauluu insan Mustafa Kyemal Atatürktün öz kolu myenyen jazllıp, anan 1927- jıldın 15oktyabrınan 20-oktyabrına çyeyinki beş kün içindye Cumuriyat Kalk Partiyasının ekinçi kurultayında okulgan kölömdüü kayrıluusu (Kiriş söz, 2-6. satır, ilk sayfa).

Önceki örneklerdeki gibi burada da "e"lerin "ye"li olarak yanlış biçimde aktarıldığı görülmektedir: менен-mуепуеn, Кемах-Kyemal, менен-mуепуеп, чейинки-с̧уеуіпкі, ичиндеiçindye. Bu örneklere karşılık бeu-beş kelimesi doğru aktarılmıştır. Peki бem-beş kelimesi, diğerleri gibi niçin "ye"li biçimde yani “byeş" olarak yazılmamıştır?

Daha evvelki örneklerde “ж”nin hatalı yazımlarına değinilmişti. Burada da жaзbı^ıınjazılıp, жыıдыı jıldın kelimeleri "c"li değil, "j"li biçim verilmiştir. Maalesef bu da önceki örneklerde olduğu gibi hatalıdır. Ancak Жумурият-Cumuriyat için aynı hatanın varlığından söz edilememektedir. Tamamen doğru bir aktarmadır. Peki aynı cümlede niçin “ж” için hem “j”li hem de “c"li aktarım görülmektedir? 
9. КНМ. Мустафа Кемал Ататүрк 1881- жылы Осмон империясынын маанидүу шаары, азыр Грецияяа караштуу Салоникиде туулган (Kiriş söz, 25-26. Satırlar, ilk sayfa).

LHM. Mustafa Kyemal Atatürk 1891- jılı Osmon impyeriyasının maanilüü şaarı, azır Greciyaga karaştuu Salonikidye tuulgan (Kiriş söz, 25-26. satırlar, ilk sayfa).

"e"nin "ye"li olarak hatalı yapılan harf aktarmaları Kемал-Kyеmal, империясынынimpyeriyasının, Салоникиде-Salonikidye örneklerinde görülmektedir.

"ц"nin "c" harfine hatalı aktırımı Грецุияга-Greciyaga kelimesinde rastlanmaktadır. Bundan başka "ж"nin "j"ye hatalı aktarımı önceki örneklerde olduğu gibi burada da karşımıza çıkmaktadır: жbıภıı-jılı.

Yukarıdaki bilgilere ilave olarak LHM'de Atatürk'ün doğum tarihi "1891" olarak verilmiştir. Böylesine kıymetli bir eserde bu hatanın olmaması gerekirdi.

10. КНМ. Инспекцияяа жиберилген кабарымда, мен "Коньяда бир кошун куралып атат дегендей кеn-сөз бар экен, кошундун ички маңызы жана уюмдашуу деңзгәэли кандай" деп сураган элем (40-42. satırlar, s. 13).

LHM. Inspyekciyaga jibyerilgen kabarımda, myen “Kon'yada bir koşun kuralıp atat dyegyendyey kyep-söz bar ekyen, koşundun mañızı jana uyumdaşuu dyeñgeeli kanday" dyep suragan elyem (7-9. satıralar, s. 14).

“e”nin "ye"li biçimde verildiği hatalı kelimeler şunlardır: Инсnекцุияza-İnspyekciyaga, жиберихген-jibyerilgen, мен-туеп, дегендей-dyegyendyey, кеn-kуер, экен-екуеп, деңзгэлиdyeñgeeli, den-dyер, элем-elyem. Bu örneklerden yola çıkıldığında жиберилген-jibyerilgen kelimesinde жибер-jibyer hatalı olarak yazılırken, aynı kelimede -zен eki ise -gen şeklinde doğru biçimde yazılmıştır. Önceki örneklerde sorulan soru tekrar karşımıza çıkmaktadır. Ele aldığımız bu eserde Kiril harfindeki "e" yi Latin harfine aktarırken neye göre "ye" ya da "e"li yazmak gerekiyor? Örneklerde tutarsızlık görülmektedir. Sık karşılaşılan diğer bir hatalı yazım ise "ж"nin "j"li biçimde aktarımıdır. Жиберихген-jibyerilgen kelimesinde kelime başının "c" olarak Latin harflerine dönüştürülmesi gerekirken "j"li biçimde yazılması hatalı bir durumdur.

Yukarıdaki cümlelerde sadece alfabe farkı olmasına rağmen cümle içinde kelime eksikliği de tespit edilmiştir. KHM'de ...кошундун "ички" маңьызы жана уюмдашуу... biçiminde geçerken LHM'de ise... koşundun mañızı jana uyumdaşuu... şeklindedir. KHM'de “ички" kelimesinin LHM'de aktarımı bulunmamaktadır. Eğer birebir harf aktarımı olacaksa, LHM'de ...koşundun "içki" mañızı jana uyumdaşuu... şeklinde olmalıydı.

11. КНМ. Ок өтпөс зоот каптап кеме жасап жатышиат, биз парустуу кемеге деле жетише элекпиз (32-33. satırlar, s. 75).

LHM. Ok ötpös zoot kaptap kyemye jasap jatışat, biz parustuu kyemye jasaganga jyetişye elyekpiz (20-21. satırlar, s. 74). 
“e”nin "ye"li biçimde verildiği hatalı kelimeler: кеме-kyemye, кемеге-kyетуе, жетишеjyetişye, элекпиз-elyekpiz.

“ж”nin kelime başında " $\mathrm{j}$ " ile yazılması da önceki örneklerde olduğu gibi hatalı bir durumdur: жасап- jasap, жатыйат- jatış, жетище- jyetişye.

KHM'de ...nарустуу "кемеге" деле "жетише"... ifadesi LHM'de ...parustuu "kyemye" jasaganga "jyetişye"... şeklinde harf aktarımı yapılmış, KHM'de кeмֻe+ze biçimi yazılmasına rağmen LHM'de yönelme hali eki olan +ge yazılmamıştır. Ayrıca KHM'de de^e kelimesinin LHM'de karşılığı bulunmayıp tamamen farklı bir kelime olan jasaganga kelimesi yazılmıştır.

12. КНМ. Корпустун башчысы Жевдат бей болсо Илияс бейдин качыр минген 52 жоокер, эки оор механизмдүү мылтык менен 9- сентябрдын таңында жолго чыкканын, 10сентябрь күнү кечинде Малатияга жетип барарын билдирген (42-45. satırlar, s. 82).

LHM. Korpustun başçısı Jyevdat byey bolso İliyas byeydin kaçır mingyen 52 jookyer, eki oor myehanizmdü̈̈ mıltık myenyen 9- syentyabrdın tañında jolgo çıkkanın, 10- sentyabr' künü kyeçindye Malatiyaga jyetip baraarın bildirgyen (28-31. satırlar, s. 81).

"e"nin "ye"li biçimde verildiği hatalı kelimeler şunlardır: Жевдаm-Jyevdat, беŭ-byey, бейдин- byeydin, минген-mingyеn, жоокер-jookyer, механизмдүү-туеhапіzmdӥӥ, мененmyenyen, сентябрдын-syentyabrdın, сентябрь- sentyabr', кечинде-kyеçindye, жетип-jyetip, билдирген- bildirgyen. Ayrıca “ж”nin kelime başında "j” ile yazılması da hatalıdır: ЖевдатJyevdat, жоокер- jookyer, жолго-jolgo, жетип- jyetip.

Bu cümle yer alan “...iki makineli tüfekle..." ifadesinin Kırgızcaya aktarması "eki oor mehanizmdüü mıltık menen" şeklinde yapılmıştır. Ancak bu aktarma yanlıştır. Doğrusu şöyledir: “...eki pulemyot menen..." diye olması gerekirdi (Abdiyev- Çolponkulova, 2006: 308). Çünkü Kırgızcada "oor mehanizmdüü mıltık” ifadesi hiçbir şeyi çağrıştırmamaktadır. Bundan dolayı Rusçadan Kırgızcaya giren "plemyot" kelimesinin kullanılması daha uygun olacaktır ki ilgili kelimenin anlamı, Kırgız Dilinin Sözlüğü'nde “aşırı hızla mermi atan otomatik silah" (KTS-II, 2011: 389) şeklindedir.

13. КНМ. 10- номерлүҮ буйрук менен элдин колунда турган төрт дөңгөлөктүҮ, жаа менен жабылган машина, төрт дөңгөлөктүҮ ат жана өгүз арабалары менен эки дөңгөлөктүҮ арабалардын бардык жабдыктары жана жаныбарлары менен бирге, унаа катары жана курал ташуу Үчүн колдонулуучу жаныбарлар, качырлар, төө менен эшектердин жыйырма пайызы алынды (41-46. satırlar, s. 407).

LHM. 10- nomyerlüü buyruk myenyen eldin kolunda turgan tört döñgölöktüü, jaa myenyen jabdılgan maşina, tört döñgölöktüü at jana ögüz arabaları myenyen eki döñgölöktüü arabalardın bardık jabdıktarı jana janıbarları myenyen birgye, unaa katarı jana kural taşuu üçün koldonuluuçu janıbarlar, kaçırlar, töö myenyen eşyektyerdin jıyırma payızı alındı (17-22. satırlar, s. 398). 
Bu son örnekte de daha öncekilerine benzer hatalar mevcuttur. Meselâ, "e"nin "ye"li biçimde verildiği hatalı kelimeler şunlardır: номерлүү-потуеrlüй, менен-туепуеп, биргеbirgye, эщектердин-еşyektyerdin.

“ж”nin kelime başında "j" ile yazılması da hatalıdır: жаa-jaа, жабылдан-jabdılgan, жанаjапа, жаныбарлары-janıbarları, жаныбарлар-janıbarlar, жыйырма-jıуıтта. Ayrıса KHМ'de жабылzан kelimesi, LHM'de jabdılgan biçiminde yazılmıştır. Muhtemelen sehven yazım söz konusudur. İlgili kelimede “d” harfi gereksizdir.

Yukarıdaki bilgilerden başka bu cümlenin Türkçeye aktarımında da bir sorun bulunmaktadır. "...elinde bulunan dört tekerlekli yaylı araba..." olan ifadenin Kirgızcaya aktarımı "...eldin kolunda turgan tört döñö̈löktüü, caa menen cabılgan maşina..." biçiminde yapılmıştır. Buradaki "yaylı araba" ifadesinin "caa menen cabılgan maşina" şeklinde aktarılması yanlıştır. Doğrusu "ressorluu araba" şeklinde olmalıdır (Abdiyev-Çolponkulova, 2006: 308). Çünkü "caa menen cabılgan maşina" denildiğinde Kırgızlarda ve Kırgızcada ne olduğu anlaşılamamaktadır.

\section{DEĞERLENIRME VE SONUÇ}

Hazırlanan bu çalışmada toplamda 13 cümleye yer verilmiş ve bu cümlelerdeki harflerin aktarımıyla ilgili bazı hatalar gösterilmeye çalışılmıştır. Alfabe aktarımıyla ilgili hatalar şöyle sıralanabilir:

a. KHM'de "E-e"ler LHM'de "ye"li biçimdedir.

b. KHM'de “Ж-ж”ler LHM'de “j”li biçimdedir.

c. KHM'de “Ц-ц”ler LHM'de “c”li biçimdedir.

Diğer taraftan kelime yahut eklerin yazımında da eksiklikler görülmektedir. Bunlar:

a. 2 numaralı örnek cümledeki KHM'de +bıнıı (+ının) ekinin LHM'de + dın şeklinde görülmesi.

b. 10 numaralı örnek cümledeki KHM'de uчкu (içki) kelimesinin LHM'de bulunmamasi.

c. 11 numaralı örnek cümledeki KHM'de naрустуy "кемеге" деле "жетише"... ifadesinin LHM'de ...parustuu "kyemye" jasaganga "jyetişye".. şeklinde verilmesi.

$\mathrm{Bu}$ çalışmanın temeli alfabe aktarımıyla ilgilidir. Ancak Taalaybek Abdiyev ve Gülzat Çolponkulova tarafından ortaklaşa hazırlanan Nutuk-Kep Kitebindegi Kotoruu Ikmaları (NutukKep Kitabındaki Aktarma Yöntemleri) adlı çalışmadan da ele aldığımız eserle ilgili bazı aktarma hataları gösterilmeye çalışıldı. Demek ki, ilgili eserde Türkçeden Kırgızcaya aktarılırken bazı hatalar bulunmaktadır. Yani eser, hem alfabe hem de cümle aktarımı konusunda hatalara sahiptir. 
Nutuk'un Kirgizcaya yapilan aktarmasında orijinal Nutuk'un hangi baskisından yapıldığı hakkına bilgi yoktur.

Eserin baş söz, kiriş söz ve mazmun kısmının numaralandırılmamış olması ve 55. sayfanın baskısındaki hatanın gözden geçirilmesi gerekmektedir.

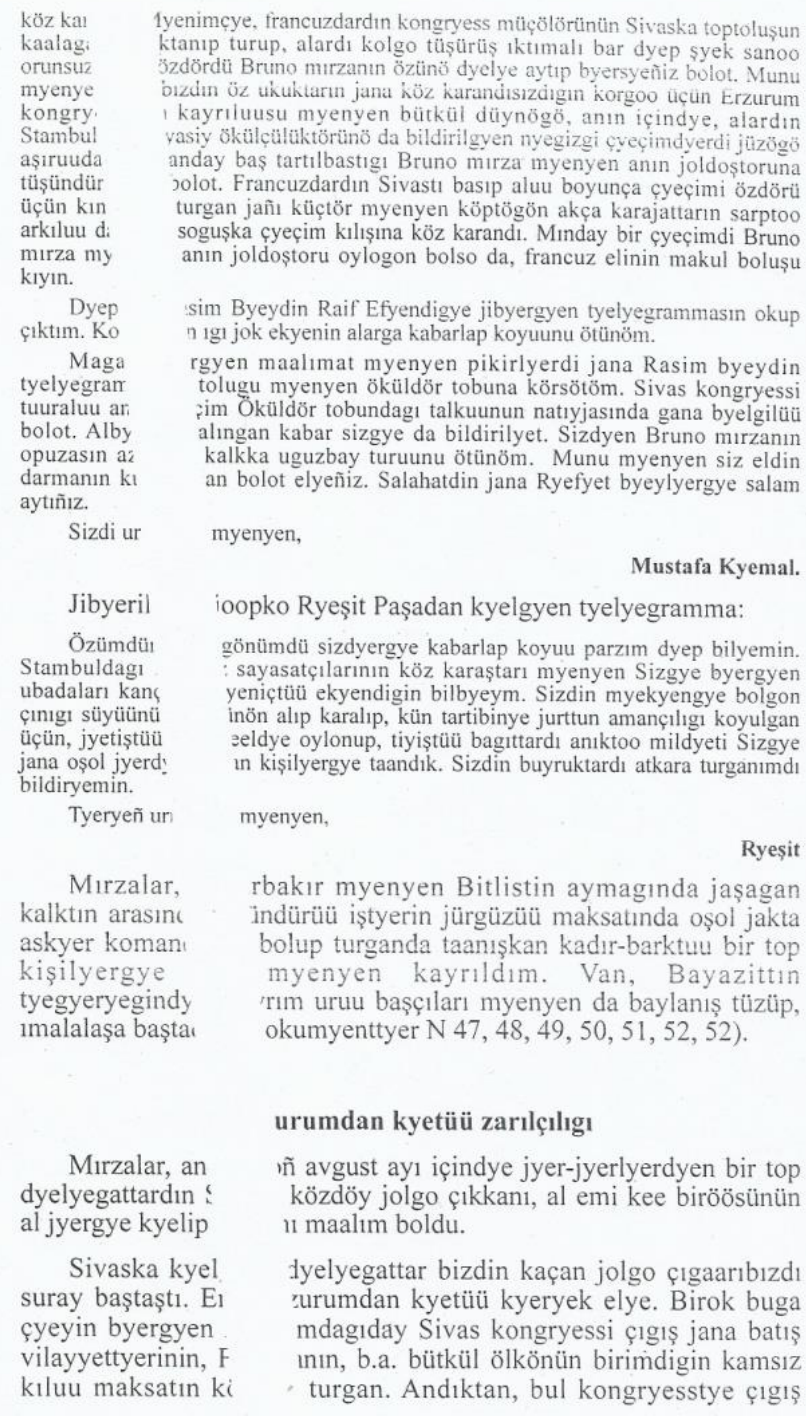

55

Resim 2. 55. sayfadaki basım hatası

Eseri Kırgızcaya aktaran Baktıgül Kalambekova, eseri Latin harflerine aktarırken kendi alfabe anlayışına göre aktarım yapıyorsa kendisinin teklif ettiği alfabe sistemini eserin başında belirtmeliydi. Bu konuyla ilgili herhangi bir bilgi yoktur.

Türkiye Cumhuriyeti Dışişleri Bakanlığı'nın desteğiyle hazırlanan böylesine kıymetli eserin hazırlanışında titiz davranılması gerekirdi. Önemli bir kurumun desteği alınmışken LHM'deki harflerin aktarımındaki sorunlar dikkatle ele alınmalıydı. Önemli bir kurum 
tarafından desteklenen bu çalışmaya gereken özenin gösterilmediği düşünülmektedir. LHM 598 sayfa olup belki gözden kaçan birkaç yazım imlâ hatası mazur görülebilir; ancak her sayfada özellikle harf çevrimi konusundaki belirsizlikler, eserin ciddiyetsizce hazırlandığını göstermektedir. Aslında sorunlar eserin kapağından itibaren başlamaktadır. 2001 yılında yayımlanan eserin alfabesi hakkında herhangi bir eleştiri tespit edilememiştir. Bu da ayrıca düşündürücü bir durumdur. Yayımlanan bu eserde son kontrollerin yapılmadığı izlenimini uyandırmaktadır. Eser daha detaylı incelenirse başka hataların da ortaya çıkması muhtemeldir.

\section{KISALTMALAR}

Haz. Hazırlayan

KHM Kiril Harfli Metin

KTS Kırgız Tilinin Sözdügü

LHM Latin Harfli Metin

s. Sayfa

TS Türkçe Sözlük

\section{KAYNAKLAR}

Abdiyev, Taalay ve Çolponkulova, Gülzat (2006). "Nutuk-Kep Kitebindegi Kotoruu Ikmaları", Kırgızistan-Türkiye Manas Üniversitesi Sosyal Bilimler Dergisi, Sayı 15, ss. 301-309.

Atatürk, Gazi Mustafa Kemal (2001). Nutuk-Kep. (Baktıgül Kalambekova, Haz.) Ankara: Tışkı İşter Ministrligi.

Atatürk, Gazi Mustafa Kyemal (2001). Nutuk-Kyep. (Baktıgül Kalambekova, Haz.) Ankara: Tışkı İştyer Ministirligi.

Kırgız Respublikasının Uluttuk İlimder Akademiyası (2011). Kırgız Tilinin Sözdügü II. Bişkek: Avrasya Press.

Türk Dil Kurumu (2011). Türkçe Sözlük. Ankara: Türk Dil Kurumu. 